\title{
Arahan Penataan Kampung Nelayan Kejawan Lor Dengan Konsep Livable Settlement Pantai Kenjeran, Surabaya
}

\author{
Guidelines of Kejawan Lor Fisher Village with Livable Settlement Concept, \\ Kenjeran Beach Surabaya
}

\author{
Fadhilah Mifta Firdaus ${ }^{1}$ \\ Universitas Diponegoro, Semarang, Indonesia \\ Nurini ${ }^{2}$ \\ Universitas Diponegoro, Semarang, Indonesia
}

\begin{abstract}
Abstrak: Livable settlement merupakan konsep pengembangan dan perancangan yang memiliki dua aspek penting sebagai acuan dasar yaitu penyediaan matapencaharian bagi masyarakat sekitar serta pemeliharaan kualitas dan keberlanjutan suatu lingkungan permukiman. Tujuan dari penelitian ini difokuskan pada arahan penataan permukiman kampung nelayan Kejawan Lor di Pantai Kenjeran Surabaya yang memiliki permasalahan yaitu lingkungan permukiman yang identik dengan kekumuhan, banjir rob, minimnya keberadaan open space, dan permasalahan sampah. Dalam penelitian ini menggunakan metode kuantitatif dengan teknik analisis deskriptif, serta teknik sampling yaitu purposive sampling. Hasil dari identifikasi dan analisisarahan penataan (UDGL) permukiman nelayan Kejawan Lor berdasarkan 6 indikator livable settlement yaitu kemudahan aksesibilitas, keberadaan perumahan yang terjangkau, peningkatan perekonomian, mendukung komunitas nelayan, sinkronisasi dengan kebijakan RDTRK Tambak Wedi tahun 2010, serta peningkatkan kualitas lingkungan. Penataan permukiman nelayan yang baik nantinya mampu mendorong peningkatan kualitas lingkungan pesisir yang berimplikasi pada produktifitas nelayan Kejawan Lor.
\end{abstract}

Kata kunci: penataan kampung nelayan; livable settlement

\begin{abstract}
Livable settlement is the concept of development and design that has two important aspects as baselines, namely the provision of livelihood for local communities as well as the maintenance of environmental quality and sustainability of a settlement. The purpose of this research is focused on settlements of Kejawan Lor fishing village, Kenjeran Beach Surabaya who have problems that neighborhoods are identical with untidiness, tidal flooding, lack of existence of the open space, and the waste problem. In this study using quantitative methods with descriptive analysis techniques, as well as the sampling technique is purposive sampling. Results of this identification and analysis will be shown to the design and guidelines of Kejawan Lor fishing village based on six indicators livable settlement is the ease of accessibility, the existence of affordable housing, an increase in the economy, supports fishing communities, synchronization with RDTRK Tambak Wedi policy in 2010, as well as the improvement of environmental quality. Good fishing settlements will be able to boost the quality of the coastal environment that have implications for the productivity of fishermen Kejawan Lor.
\end{abstract}

Keywords: guidelines of kampung nelayan; livable settlement

\footnotetext{
1 Korespondensi Penulis: Universitas Diponegoro, Semarang, Indonesia

Email: fadhilahmiftafirdaus@gmail.com

2 Korespondensi Penulis: Universitas Diponegoro, Semarang, Indonesia

Email: dsuwandono@gmail.com
} 


\section{Pendahuluan}

\section{Gambaran Umum Kampung Nelayan Kejawan Lor}

Permukiman kampung nelayan Kejawan Lor ini menjadi kawasan permukiman masyarakat nelayan Kota Surabaya yang tumbuh secara alami dan membentuk struktur ruang yang sangat organik. Fenomena migrasi juga sangat dirasakan pada kampung nelayan Kejawan Lor, yaitu banyaknya masyarakat yang merupakan penduduk asli Madura yang menggantungkan hidupnya di Kota Surabaya dan tinggal di kampung nelayan Kejawan Lor. Oleh karena itu, pertumbuhan dan perkembangan permukiman kampung nelayan Kejawan Lor tersebut tidak didukung dengan pemenuhan sarana prasarana dasar permukiman yang baik, sehingga makin menuntun kampung kampung nelayan Kejawan Lor berada pada lingkungan yang identik dengan kekumuhan. Permasalahan lain yaitu terkait degradasi lingkungan yang di akibatkan dari perkembangan lingkungan yang tidak terkendali, yaitu antara lain banjir rob, abrasi, intrusi air laut, dan penurunan muka tanah, serta masalah persampahan. Selain itu, minimnya keberadaan ruang terbuka hijau ataupun open space sebagai sarana komunitas sosial penduduk hampir tidak dapat ditemui di kampung nelayan Kejawan Lor. Berdasarkan permasalahan-permasalahan tersebut lingkungan permukiman di kampung nelayan Kejawan Lor menjadi tidak kondusif atau dapat dikatakan jauh dari lingkungan permukiman yang memanusiakan manusianya, sehingga makin membuat kejenuhan di lingkungan tempat tinggal penduduk kampung nelayan Kejawan Lor. Oleh karena itu, diperlukan perancangan kawasan permukiman kampung nelayan Kejawan Lor dengan konsep livable settlement yang dituangkan dalam alternatif desain perancangan atau Urban Design Guidelines (UDGL). Penerapan konsep perancangan tersebut diharapkan mampu mengarahkan permukiman kampung nelayan Kejawan Lor yang nyaman sebagai tempat tinggal dalam lingkup kawasan pesisir.

Kampung nelayan Kejawan Lor berada dalam lingkup administrasi Kelurahan Kenjeran, Kecamatan Bulak. Kampung nelayan Kejawan Lor masuk ke RW 2 di Kelurahan Kenjeran. Lokasinya sangat berdekatan dengan Taman Hiburan Pantai Kenjeran, sehingga kawasannya diperuntukan sebagai zona permukiman, pariwisata, serta perdagangan dan jasa.

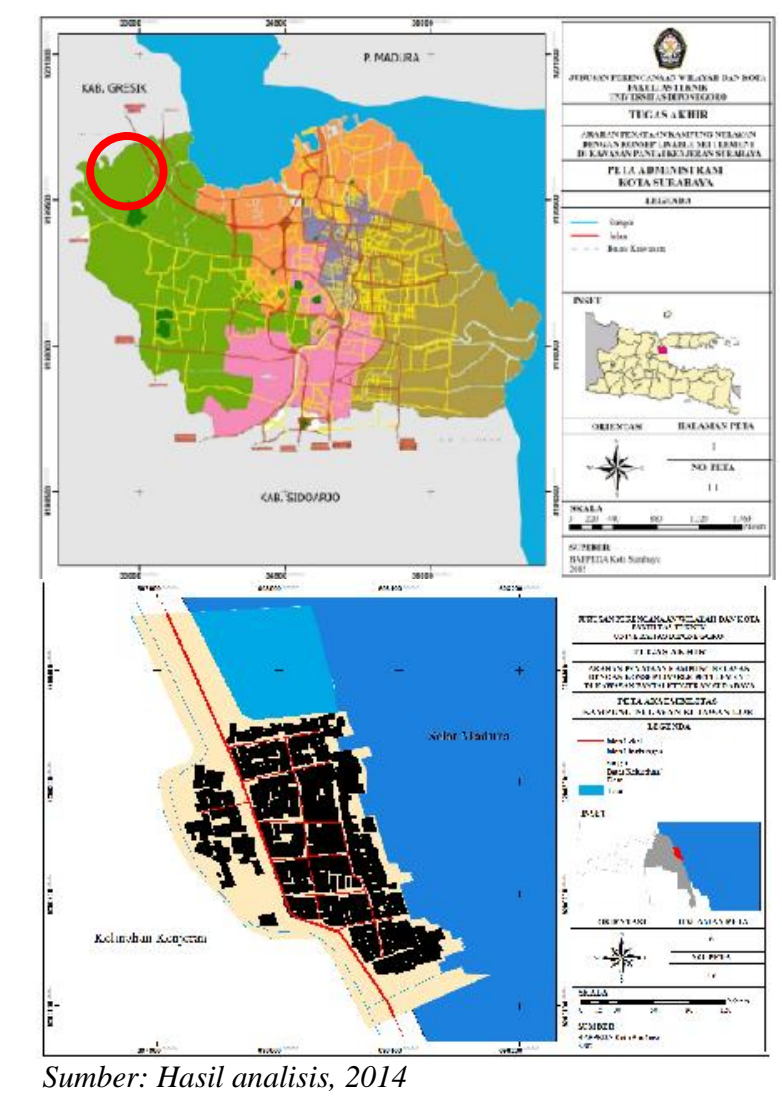

Gambar 1. Tinjauan Lokasi Kampung Nelayan Kejawan Lor 
Berdasarkan hasil tinjauan dari Kepmen PU No. 20/KPTS/1985 tentang Pedoman Teknis Pembangunan Perumahan Sederhana Tidak Bersusun, diketahui bahwa kepadatan rumah di kampung nelayan Kejawan Lor termasuk ke dalam kategori tinggi. Dalam hal ini, tingkat konsentrasi bangunan di kawasan kampung nelayan Kejawan Lor sangat padat dengan batas antar kavling rumah warga yang hampir tidak jelas terlihat. Selain itu, banyak rumah penduduk yang menjorok dan memakan area bibir pantai, disamping sebagai tempat pemberhentian kapal-kapal nelayan. Fakta lainnya adalah bahwa rumah-rumah yang dibangun 30 meter dari tepi perairan menggunakan tanah urug, sehingga masyarakat Kejawan Lor menambah daratan dengan mengurug tanah lalu mendirikan bangunan rumah mereka.
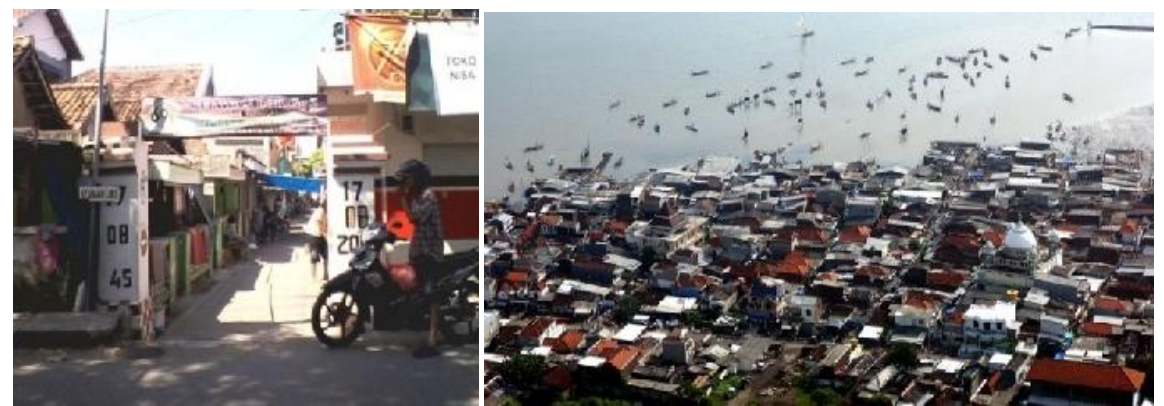

Sumber: Hasil observasi, 2015 (kiri); Mongabay, 2014 (kanan)

Gambar 2. Kondisi Permukiman Kampung Nelayan Kejawan Lor

\section{Metode Penelitian}

\section{Permukiman Nelayan dan Livable Settlement dalam Kajian Literatur}

Metode penelitian kuantitatif dengan teknik analisis deskriptif bertujuan untuk menjelaskan dan meringkaskan berbagai kondisi atau situasi dari berbagai variabel yang timbul berdasarkan objek penelitian (Bungin, 2005). Sesuai dengan fokus penelitian ini yaitu arahan penataan permukiman kampung nelayan Kejawan Lor masuk ke dalam lingkup penelitian kuantitatif dengan teknik analisis deskriptif. Dalam penelitian ini, menggunakan jenis analisis deskripsi yaitu studi kasus, yaitu bahwa penelitian hanya menggunakan kasus tertentu pada wilayah tertentu sebagai objek penelitian. Adapun penelitian ini fokus kepada arahan penataan permukiman kampung nelayan Kejawan Lor, sehingga metode yang digunakan bersifat kasuistik terhadap objek penelitian tersebut.

Undang-Undang RI No.4 Tahun 1992 tentang Perumahan dan Permukiman, mendefiniskan rumah sebagai salah satu kebutuhan dasar manusia akan papan merupakan bagian dan perumahan dan permukiman yang perlu ditata agar dapat berkelanjutan, serta dapat meningkatkan kesejahteraan penghuni di dalamnya karena akan menunjang pembangunan ekonomi, sosial budaya dan bidang-bidang yang lain. Dalam hal ini, Doxiadis (1971) mendefinisikan permukiman atau human settlement sebagai suatu tempat (ruang) untuk hidup dan berkehidupan bagi kelompok manusia. Adapun terkait perkampungan nelayan, terdapat definisi yaitu sebuah perkampungan yang berlokasi di kawasan perairan laut atau kawasan penangkapan ikan dengan perekonomian yang berbasis pada kegiatan perikanan tangkap dan pemrosesan ikan (Tietze, 2000).

Konsep livable settlement merupakan suatu konsep perancangan yang menggabungkan antara konsep livability dan aspek permukiman (settlement). menurut Evan (2002), konsep livable digunakan untuk mewujudkan bahwa gagasan pembangunan sebagai peningkatan dalam kualitas hidup membutuhkan fisik maupun habitat sosial untuk realisasinya. Sedangkan pengertian permukiman menurut Doxiadis (1971) adalah sebuah sistem yang terdiri dari lima unsur yaitu alam (nature), manusia (man), kehidupan sosial (society), ruang (shell), dan jaringan (network). Konsep livable settlement percaya bahwa jika penyediaan lapangan kerja dan permukiman tidak memperhatikan aspek lingkungan, maka akan terjadi degradasi lingkungan yang lambat laun akan mengganggu kegiatan masyarakat di dalamnya, terutama dalam kegiatan bekerja. 
Penerapan Konsep Livable Settlement pada Kampung Nelayan Kejawan Lor

\section{Analisis Perancangan Permukiman Kampung Nelayan Kejawan Lor}

Penerapan konsep livable settlement mencoba menjadi solusi bagi permasalahan penataan kampung nelayan Kejawan Lor yaitu antara lain lingkungan permukiman yang kumuh, degradasi lingkungan seperti banjir rob, abrasi, intrusi air laut, dan penurunan muka tanah, minimnya keberadaan ruang terbuka hijau dan open space sebagai sarana komunitas sosial penduduk, serta adanyan permasalahan sampah.

Di samping itu, penerapan konsep livable settlement fokus pada bagaimana menciptakan lingkungan permukiman bagi nelayan Kejawan Lor yang nyaman untuk ditinggali dan bekerja. Oleh karena itu, perlu adanya keterhubungan antara tempat bekerja nelayan dan tempat tinggal bagi nelayan Kejawan Lor agar masyarakat nelayan merasakan livable pada lingkungan permukimannya. Perumahan masyarakat nelayan yang sebelumnya berada pada tepian pantai secara landed house direlokasikan ke barat jalan dengan bentuk rumah susun. Sedangkan sarana penunjang aktivitas nelayan akan ditingkatkan dengan menyediakan TPI, balai pertemuan nelayan, tempat penjemuran ikan dan jarring, tempat pengasapan ikan, dermaga bagi kapal nelayan, serta bengkel. Adapun gambar berikut ini mengilustrasikan keterhubungan aktivitas ruang sesuai dengan pola sehari-hari masyarakat nelayan yang disinkronasikan dengan konsep livable settlement.

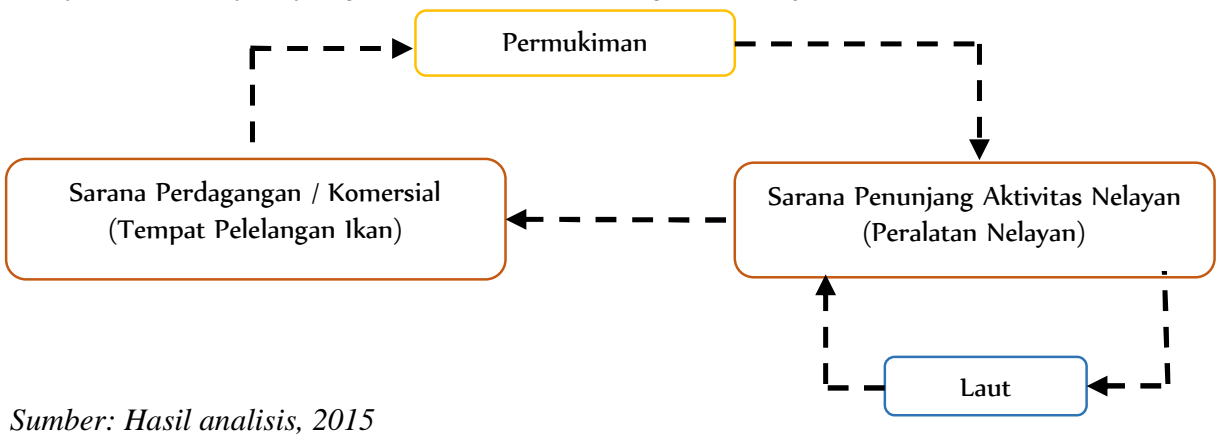

Gambar 3. Keterhubungan Aktivitas Ruang

1. Analisis aktivitas dan pengguna: Pengguna utama kampung nelayan Kejawan Lor adalah masyarakat nelayan berjumlah 1.230 jiwa. Adapun aktivitas di wilayah penelitian fokus pada aktivitas nelayan di pantai serta pola pergerakan masyarakat kampung nelayan Kejawan Lor yang dibagi fungsi aktivitas menjadi 3 yaitu fungsi utama, penunjang, dan pelayanan.

2. Analisis kebutuhan ruang: Berdasarkan perhitungan carrying capacity, kampung nelayan Kejawan Lor dengan luas 5,14 Ha terbagi antara ruang terbangun $47 \%$ $(2,42 \mathrm{Ha})$ dan non terbangun $53 \%(2,71 \mathrm{Ha})$. Pada ruang terbangun terbagi lagi lahan terbangun 1,34 Ha dan sirkulasi 30\% yaitu 1,08 ha. Dalam hal ini asumsi kebutuhan ruang per jiwa adalah $15 \mathrm{~m}^{2}$ sehingga didapatkan carrying capacity 1.613 jiwa yang dapat ditampung.

3. Analisis hubungan antar aktivitas: Fungsi aktivitas permukiman merupakan fungsi utama, sehingga aktivitas permukiman memiliki keterkaitan yang lebih banyak dengan aktivitas lain seperti dengan posyandu, balai pertemuan, dan lain-lain.

4. Analisis organisasi ruang: Permukiman sebagai fungsi utama merupakan hirarki tertinggi dalam organisasi ruang, sedangkan fungsi penunjang permukiman, fungsi pendukung aktivitas nelayan, dan fungsi pelayanan berada pada hirarki yang lebih rendah.

5. Analisis tapak: Analisis menghasilkan zoning kawasan kampung nelayan Kejawan Lor yang terdiri dari 5 zon yaitu zona permukiman, zona sarana pendukung aktivitas nelayan, zona RTH, zona RTNH, dan sarana penunjang permukiman.

6. Analisis penyediaan infrastruktur:jalan eksisting (Jalan Pantai Kenjeran) akan dikonsolidasi lahan yang sebelumnya menikung menjadi lurus. Adapun jalan dilakukan perlebaran menjadi 6 meter, dan ditambah jalur pejalan kaki selebar 1,5 meter dengan penambahan streets furniture seperti lampu jalan, bangku, halte, dan lain-lain. Penyediaan jaringan listrik, air, dan telepon menggunakan sistem underground. 


\section{Analisis elemen perancangan kota:}

- Land Use: Penentuan tata guna lahan disesuaikan dengan zoning kawasan.

- Building Form and Massing: bentuk bangunan permukiman akan diarahkan menjadi rumah susun dengan tinggi 6 lantai, sedangkan untuk bangunan sarana penunjang dan pelayanan permukiman dan nelayan memiliki tinggi 1-2 lantai.

- Circulation and Parking: Adanya pembagian ruang di kampung nelayan Kejawan Lor yaitu bagi penghuni rumah susun area parkir di besmen, sedangkan untuk pengangkutan barang dan hasil laut diletakkan di zona sarana pendukung nelayan.

- Open Space: Penyediaan RTH aktif yaitu taman lingkungan (jogging track, sitting area, dan playground) dan RTH pasif yaitu green belt pada tepian jalan dan sebagai pemisah antar zona.

- Pedestrian Ways: Jalur pejalan kaki memiliki ukuran 1,5 meter dan dilengkapi jalur untuk difabel people.

- Activity Support: Penyediaantoko pada bangunan lantai 1 rumah susun.

- Signage: Penempatan papan penanda TPI dan balai pertemuan nelayan di tepi jalan, namun juga harus memperhatikan penataan signage agar tetap terjaga nilai estetika kawasan.

8. Analisis kriteria tak terukur:

- Access: Penentuan side entrance (SE) di bagian utara dan main entrance (ME) di bagian selatan, penambahan landmark berupa gapura pada main dan sideentrance, mempertahankan akses eksisting kawasan karena keterkaitan dengan kawasan wisata Pantai Kenjeran.

- Compatibility: Rumah penduduk direlokasi ke sebelah barat jalan menjadi rumah susun, penambahan taman dan vegetasi pada lahan bekas bangunan rumah.

- View. Pemandangan laut menajadi poin utama yang dapat langsung dilihat dari jalan tanpa adanya penghalang.

- Identity: Penambahan landmark dan signage untuk menciptakan sense of placekampung nelayan Kejawan Lor.

- Sense: Penanaman vegetasi pesisir untuk memperkuat suasana kawasan Pantai Kenjeran.

- Livability: penyediaan halte angkutan umum bagi masyarakat, penyediaan rumah susun dan meningkatkan prasarana permukiman (drainase, asir bersih, dll.), penyediaan sarana pendukung aktivitas nelayan (dermaga, penjemuran ikan dan jaring, dll.), penyesuaian dengan RDTRK Tambak Wedi, serta melakukan peremajaan kawasan dari bangunan lama menjadi RTH.

9. Analisis kriteria terukur:Menghasilkan KDB 89\%, KLB 7 lantai (asumsi 1 lantai 4 meter) namun yang digunakan 6 lantai, Jarak antar bangunan adalah 6 meter, GSB 13-36 meter.

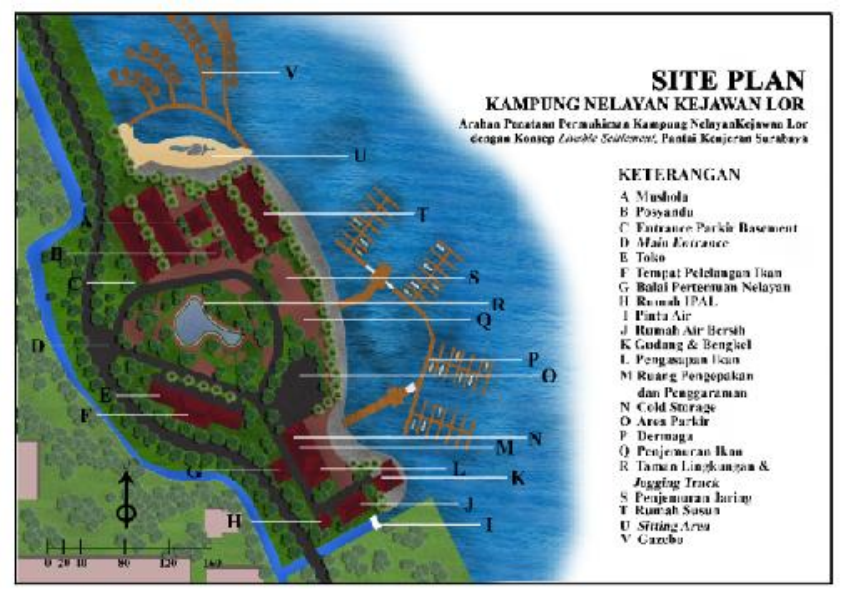

Sumber: Hasil analisis, 2015

Gambar 4. Site Plan Kawasan 
Tabel 1. Kebutuhan Ruang

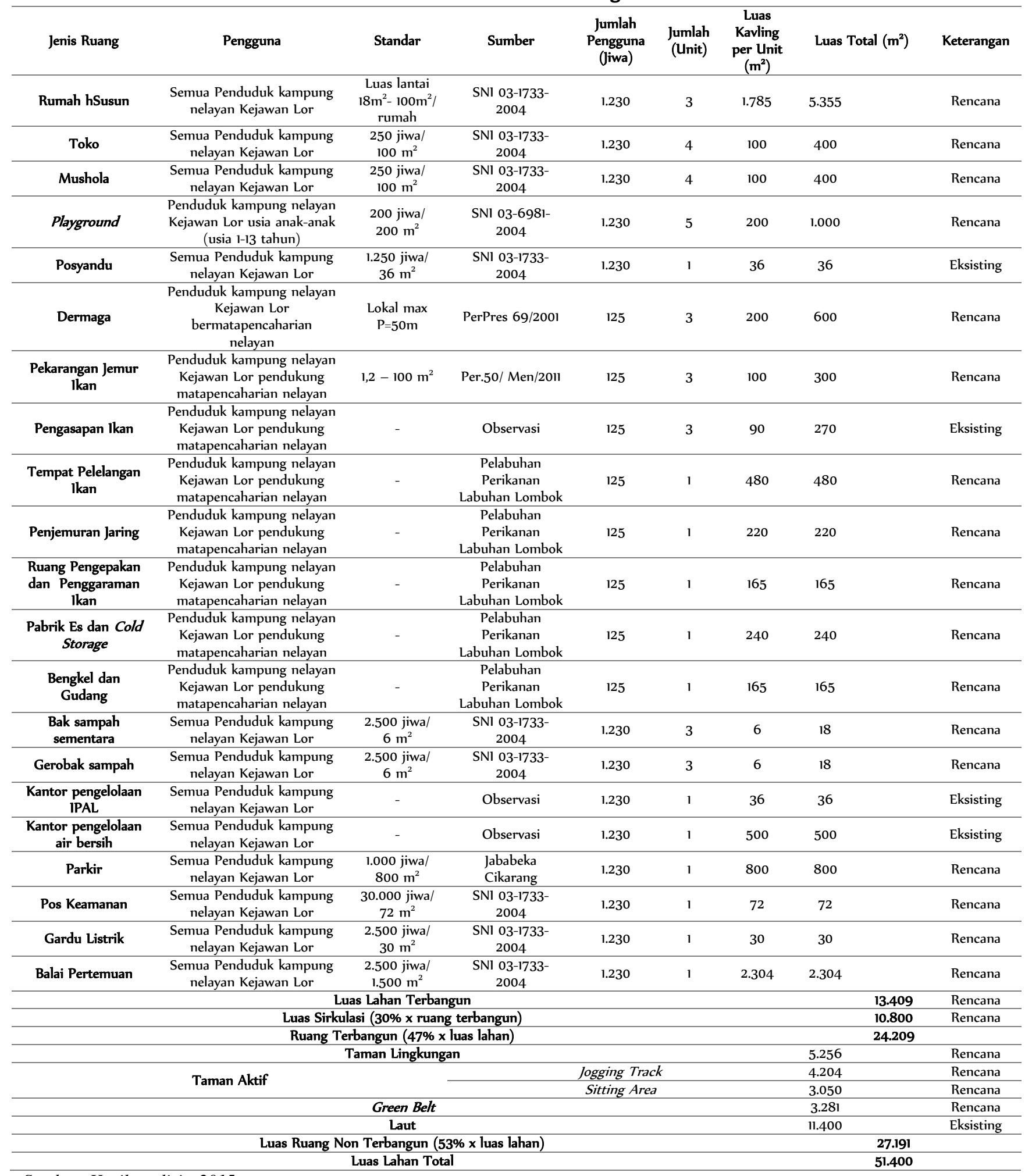

Sumber: Hasil analisis, 2015

Analisis Hirarki Proses

Dalam penelitian ini, peneliti memilih 3 orang pakar atau ahli yang dianggap memahami mengenai bidang perencanaan dan perancangan permukiman. Adapun dari pakar atau ahli tersebut akan didapatkan tanggapan atau masukan terkait penambahan atau pengurangan desain penataan. Penilaian didasarkan pada 6 indikator livability sesuai dengan alur metode AHP berikut: 


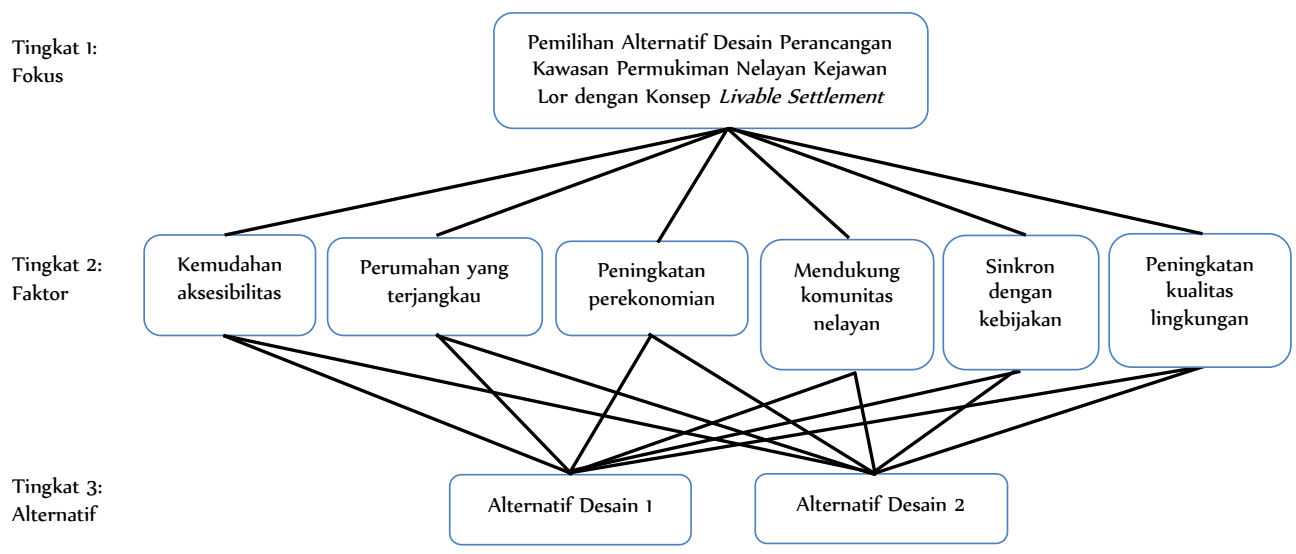

Sumber: Hasil Analisis, 2015

Gambar 5. Alur Metode AHP

Tabel 2. Rata-rata Hasil Perhitungan Penilaian Narasumber Ahli

\begin{tabular}{ccccc}
\hline \multirow{2}{*}{ No } & Kriteria & \multicolumn{2}{c}{ Nilai PV } & Nilai \\
\cline { 3 - 4 } & & Desain 1 & Desain II & lnkonsistensi \\
\hline $\mathbf{1}$ & Narasumber 1 & 0.278 & 0.722 & 0.00 \\
\hline $\mathbf{2}$ & Narasumber II & 0.833 & 0.167 & 0.00 \\
\hline 3 & Narasumber III & 0.167 & 0.833 & 0.00 \\
\hline & Rata-rata & 0.426 & 0.574 & 0.00 \\
\hline
\end{tabular}

Sumber: Hasil Analisis, 2015

Berdasarkan hasil analisis penghitungan menggunakan Expert Choice, maka didapat nilai inkonsistensi dari masing-masing narasumber adalah 0 , hal ini berarti bahwa dari keempat narasumber sudah konsisten dan memiliki pengetahuan yang baik mengenai objek yang dinilai. Adapun berdasarkan hasil perhitungan, rata-rata desain 11 lebih besar daripada desain 1 . Oleh karena itu, berdasarkan pendapat para pakar, desain 11 dianggap lebih sesuai untuk diterapkan di kampung nelayan Kejawan Lor dan selanjutnya dapat dibuat arahan perancangan kawasan (UDGL).

UDGL Kampung Nelayan Kejawan Lor dengan Konsep Livable Settlement Konsep perancangan pada kawasan kampung nelayan Kejawan Lor adalah livable settlement. Penerapan konsep livable settlement fokus pada bagaimana menciptakan lingkungan permukiman bagi nelayan Kejawan Lor yang nyaman untuk ditinggali dan bekerja. Oleh karena itu, perlu adanya keterhubungan antara tempat bekerja nelayan dan tempat tinggal bagi nelayan Kejawan Lor agar masyarakat nelayan merasakan livable pada lingkungan permukimannya. Adapun berikut ini merupakan arahan penataan permukiman kampung nelayan Kejawan Lor.

Tabel 3. UDGL Livable Settlement pada Permukiman Kampung Nelayan Kejawan Lor

\begin{tabular}{|c|c|c|c|c|}
\hline No & 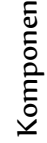 & $\begin{array}{c}\text { Tujuan } \\
\text { Penataan }\end{array}$ & Arahan Penataan & Desain \\
\hline
\end{tabular}

- Area parkir ini diperuntukan bagi kendaraan nelayan berjenis truk dan mobil sebagai moda penganggkut hasil laut untuk

$\begin{array}{ccc}\frac{\hbar}{\frac{i}{\pi}} & \begin{array}{c}\text { Kemudahan } \\ \text { aksesibilitas }\end{array} \\ \text { 1. } & \begin{array}{c}\text { bagi } \\ \frac{d}{2}\end{array} & \text { masyarakat }\end{array}$
didistribusikan ke luar

- Area parkir ini juga diperuntukan

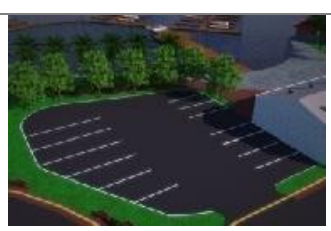
bagi kendaraan para pengunjung TPI (Tempat Pelelangan lkan)

- Sedangkan rea parkir untuk masyarakat Kejawan Lor diarahkan pada parkir basemen yang terletak di bawah gedung rumah susun 


\section{Kesimpulan}

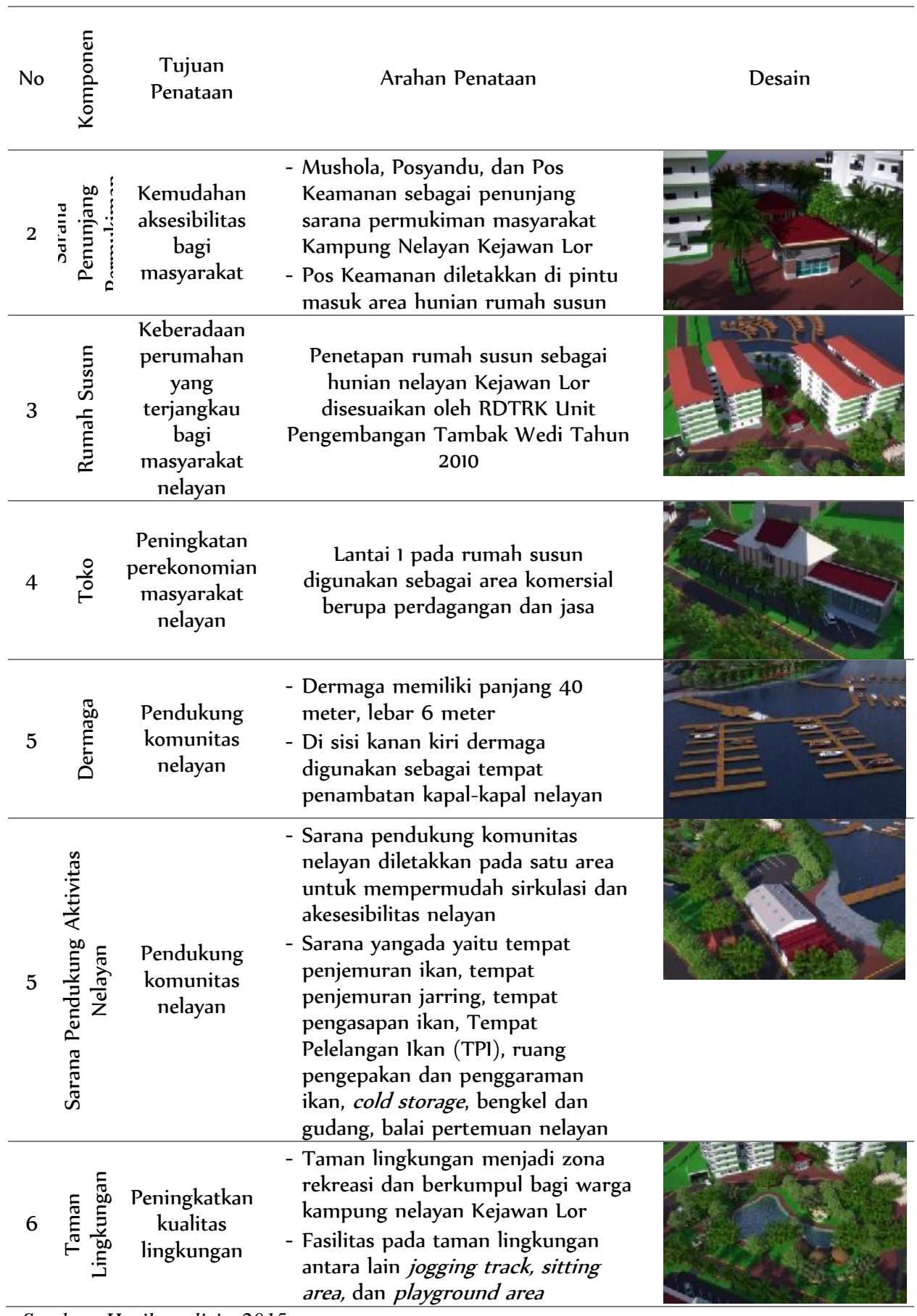

- Mushola, Posyandu, dan Pos Keamanan sebagai penunjang sarana permukiman masyarakat Kampung Nelayan Kejawan Lor

Pos Keamanan diletakkan di pintu Penetapan rumah susun sebagai hunian nelayan Kejawan Lor disesuaikan oleh RDTRK Unit 2010

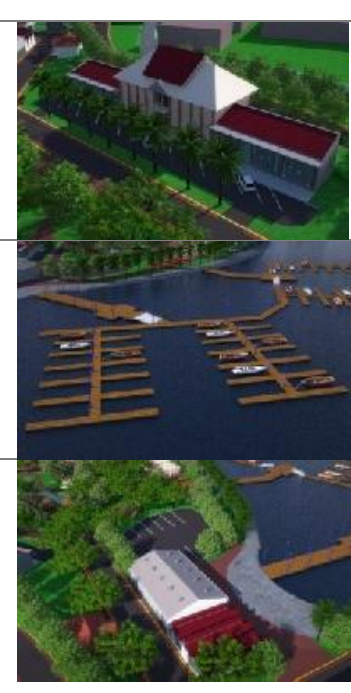
penjemuran jarring, tempat pengasapan ikan, Tempat pengepakan dan penggaraman ikan, cold storage, bengkel dan gudang, balai pertemuan nelayan

Taman lingkungan menjadi zona rekreasi dan berkumpul bagi warga kampung nelayan Kejawan Lor antara lain jogging track, sitting area, dan playground area

Sumber: Hasil analisis, 2015

Konsep perancangan dalam penelitian ini adalah livable settlement yaitu konsep pengembangan dan perancangan kawasan yang memiliki dua aspek penting sebagai menjadi acuan dasar yaitu penyediaan tempat bekerja masyarakatnya (nelayan) serta memelihara kualitas dan keberlanjutan (menjaga keberadaan dan kualitas ruang terbuka) pada kawasan permukiman kampung nelayan Kejawan Lor, sehingga terjamin kegiatan masyarakat yang aman dan nyaman untuk ditinggali oleh seluruh masyarakat nelayan Kejawan Lor.

Adapun berdasarkan hasil penilaian ahli dengan AHP, didapatkan desain terpilih adalah desain 2 yang selanjutnya dibuat UDGL kawasan. Adapun panduan rancang kota (UDGL) dengan konsep livable settlement berusaha untuk menjadi solusi dari permasalahan yang ada di kampung nelayan Kejawan Lor, terkait segi

RUANG (VOL.1) NO. 4, 2015, 201 - 210

DOI: HTTP://DX.DOI.ORG/10.14710/RUANG.1.4.201-210 
fisik kawasan maupun non fisik yang mempengaruhi lingkungan permukiman. Berikut ini merupakan panduan rancang kota (UDGL) pada kampung nelayan Kejawan Lor:

1. Tata Guna Lahan. Pada rencana tata guna lahan kampung nelayan Kejawan Lor dibagi menjadi 6 kawasan, yaitu zona permukiman (untuk tempat tinggal masyarakat nelayan Kejawan Lor dengan rumah susun), zona sarana pendukung aktivitas nelayan (terdiri tempat penjemuran jaring dan ikan, dan lain-lain), zona RTH (dimanfaatkan sebagai ruang rekreasi bagi masyarakat kampung nelayan Kejawan Lor yang di dalamnya terdapat taman lingkungan, jogging track, dan sitting area), zona RTNH (perairan laut), zona sarana penunjang permukiman (terdiri dari posyandu, pos keamanan, dan lain-lain), serta zona perdagangan (terdiri dari pertokoaan dan TPI).

2. Intensitas Pemanfaatan Lahan. Ketentuan KDB kawasan permukiman kampung nelayan Kejawan Lor adalah 85\% serta KLB adalah 1-6 lantai.

3. Bentuk dan Massa Bangunan. Pembangunan permukiman rumah susun dengan ketinggian 6 lantai. Garis sempadan untuk semua bangunan di kampung nelayan Kejawan Lor (Jalan Pantai Kenjeran) adalah 16 meter dengan jarak antar bangunan adalah 6 meter.

4. Sirkulasi dan parkir. Sistem sirkulasi dibagi antara sirkulasi angkutan barang dan orang. Sirkulasi angkutan barang diarahkan pada bagian utara (agar tidak mengganggu zona permukiman). Parking area untuk barang dan jasa diletakkan dalam zona sarana pendukung aktivitas nelayan, sedangkan parking area untuk masyarakat penghuni rumah susun dengan konsep parkir besmen.

5. Ruang Terbuka. Ruang terbuka terdiri dari RTH aktif (taman lingkungan, jogging track, dan sitting area) dan RTH pasif (green belt).

\section{Rekomendasi}

\section{Daftar Pustaka}

Rekomendasi yang dapat diberikan kepada stakeholder terkait dalam arahan penataan kampung nelayan Kejawan Lor dengan konsep livable settlement di kawasan Pantai Kenjeran Surabaya antara lain sebagai berikut:

1. Terkait kebijakan penentuan zona relokasi rumah susun dalam RDTRK Tambak Wedi tahun 2010 yang menyatakan perelokasian rumah penduduk menjadi rumah susun ke barat jalan perlu dikaji lebih lanjut, karena pada kondisi tapak kampung nelayan Kejawan Lor kurang memadahi jika dilakukan perelokasian sesuai dengan kebijakan RDTRK Tambak Wedi tahun 2010.

2. Perlu adanya pengintegrasian antara zona permukiman, zona sarana penunjang aktivitas nelayan, serta zona rekreasi (taman lingkungan) oleh pihak swasta dan utamanya masyarakat kampung nelayan Kejawan Lor, agar masyarakat kampung nelayan Kejawan Lor mampu menjalankan sistem permukiman sesuai dengan konsep livable settlement.

3. Perlu adanya kerjasama antara pengelola sarana penunjang aktivitas nelayan (TPI), pemerintah dan pihak swasta dalam mengembangkan dan mengelola sarana penunjang aktivitas nelayan (TPI) agar mampu meningkatkan perekonomian dan kesejahteraan masayarakat kampung nelayan Kejawan Lor.

4. Peningkatan penghijauan pada lingkungan permukiman kampung nelayan Kejawan Lor, terutama pada kawasan yang dilakukan peremajaan kawasan bekas permukiman landed house eksisting.

5. Penyuluhan dan pemahaman kepada masyarakat kampung nelayan Kejawan Lor oleh pihak pemerintah maupun LSM terkait perubahan pola aktivitas dan perilaku dari landed house menjadi rumah susun.

6. Pengawasan dan penindaktegasan pada pihak-pihak atau masyarakat kampung nelayan Kejawan Lor dan sekitarnya yang melanggar peraturan di lingkungan kampung nelayan Kejawan Lor, yaitu seperti membuang sampah sembarang ke sungai atau laut, merusak properti umum, dan lain sebagainya.

BAPPEDA. 2010. Rencana Detail Tata Ruang Kota Unit Pengembangan Tambak Wedi Tahun 2010. Badan Perencanaan Pembangunan Daerah Propinsi Jawa Timur.

2010. Rencana Tata Ruang Wilayah Kota Surabaya Tahun 2010-2030. Badan Perencanaan Pembangunan Daerah Propinsi Jawa Timur.

Bungin, M. Burhan Prof. Dr. S.Sos MSi. 2006. Metodologi Penelitian Kuantitatif. Jakarta: Kencana. 
Cambridge Systematicz, Inc. 2015. "What Is the Difference between Livability and Sustainability?". Cambridge Systematicz. http://www.camsys.com/kb_experts_livability. htm. Diakses pada tanggal 12 Februari 2015.

Doxiadis, CA. 1971. Ekistics - An Introduction to the Science of Human Settlements. London: Hutchinson

Evans, Peter. 2002. Livable Cities? Urban Struggles for Livelihood and Sustainability. California: University of California Press.

Keputusan Menteri Pekerjaan Umum Nomor 20 Tahun 1985 tentang Pedoman Teknis Pembangunan Perumahan Sederhana Tidak Bersusun

Lynch, Kevin. 1981. Good City Form. Cambridge: MIT Press

Saaty, Thomas 1. 1986. Decision Making for Leaders The Analytical Hierarchy Process for Decision in Complex World. University of Pitsburgh.

Shirvani, Hamid. 1985. The Urban Design Process. New York: Van Nostrand Reinhold Company.

Suwandono, Djoko. 1988. "Beberapa Konsep Pemikiran Terhadap Pengarahan bagi Penjabaran Rencana Dua Dimensi menjadi Tiga Dimensi" Tesis, Program Perencanaan Wilayah dan Kota, Fakultas Pasca Sarjana ITB, Bandung.

Tietze, U., Groenewold, G. and Marcoux, A. 2000. Demographic change in coastal fishing communities and its implications for the coastal environment. Fisheries Technical Paper 403. Rome. http://www.fao.org/docrep/005/X8294E/X8294E00.htm\#TOC. Diakses pada tanggal 2 Desember 2014.

Undang-Undang Republik Indonesia Nomor 4 Tahun 1992 tentang Perumahan dan Permukiman.

United Kingdom Building Research Establishment. 1977. Third World Urban Housing. Watford: Building Research Establishment. pp. 225-228.

Untermarn, R. dan R. Small. 1977. Site Planning for Cluster Housing. Terjemahan Vincen M. Bandung: Intermedia.

Urban Design Plan of San Francisco. 1970. City Planning. San Francisco, California: Dept. of City Planning 